\title{
Conflicting management policies for the Arabian wolf Canis lupus arabs in the Negev Desert: is this justified?
}

\author{
Orly Cohen, Adi Barocas and Eli Geffen
}

\begin{abstract}
Conservation plans may conflict when both predator and prey in the same ecological system are threatened species. In this study we present a problematic case of conflicting conservation policies involving the Arabian wolf Canis lupus arabs and two species of gazelles (Gazella gazella acaciae and Gazella dorcas), all of which are threatened in Israel. By studying genetic subdivision using faecal DNA we evaluated the policy of treating the Arabian wolves in the Negev Desert as two separate populations. We analysed 95 wolf faecal samples from 12 feeding sites c. $20 \mathrm{~km}$ apart. Network analysis and Bayesian clustering were used for separating populations. Mark-recapture design, rarefaction and an urn model were applied to estimate wolf population size. We found that wolves in the central and southern Negev cannot be genetically separated, and their density is similar in both regions. Our results provide a better baseline for a unified management of wolves in the Negev. We call for the consideration of other factors influencing gazelle population size before adopting drastic measures such as wolf removal.
\end{abstract}

Keywords Carnivore removal, Israel, Middle East, noninvasive sampling, population size, population subdivision, scatology

This paper contains supplementary material that can be found online at http://journals.cambridge.org/orx

\section{Introduction}

great deal of effort goes into protecting threatened $A_{\text {and/or important species. In some cases several }}$ threatened species can be protected under the same programme. Nevertheless, when these threatened species include both predator and prey in the same ecological system there may be potential conflict of management plans. This is illustrated by examples from the Channel Islands off the Californian coast. These islands were previously densely populated by the island fox Urocyon

Orly COHEN, AdI BAROCAS* and Eli GEFFEN (Corresponding author) Department of Zoology, Tel Aviv University, Tel Aviv 69978, Israel. E-mail geffene@post.tau.ac.il

* Also at: Program in Ecology and Department of Zoology and Physiology, University of Wyoming, Laramie, Wyoming, USA

Received 3 August 2011. Revision requested 25 November 2011.

Accepted 6 December 2011. littoralis. The arrival and spread of the golden eagle Aquila chrysaetos to these islands in the 1980s, facilitated by the availability of the previously introduced feral pig Sus scrofa as prey, led to a drastic decline in fox numbers (Roemer et al., 2002), to the point that breeding programmes were established to save the fox from extinction. The dilemma was: should the golden eagle, which is a protected species, be removed to save another protected species, the island fox? To mitigate the decline in fox numbers, golden eagles were translocated, and feral pigs eradicated from the islands (Courchamp et al., 2003). A similar case in these Channel Islands is that of the threatened San Clemente loggerhead shrike Lanius ludovicianus mearnsi, which is predated by the island fox; a control programme was established to save the shrike (Roemer \& Wayne, 2003).

Predator removal is commonly practised by wildlife managers. A recent review suggested that predator removal increased hatching and fledging success and breeding populations of birds (Smith et al., 2010). Predation by wolf Canis lupus, puma Puma concolor and coyote Canis latrans may be a significant mortality factor for medium or large ungulates (e.g. deer, caribou Rangofer tarandus, moose Alces alces) in some areas under certain conditions (reviewed in Ballard et al., 2001). A predator removal programme may not affect prey populations that are near carrying capacity but may significantly increase ungulate populations that are substantially below carrying capacity. Thus results of predator removal practice are confounded by numerous factors and only through intensive studies can predation be identified as a major limiting factor (Ballard et al., 2001). Wasser et al. (2011) studied the effect of predator removal on caribou populations and concluded that management should prioritize the control of human activities before implementation of more extreme actions such as removal of wolves. In other words, resource selection and its physiological consequences can significantly influence predatorprey interactions, and should be considered in management programmes that aim to manipulate complex ecosystems.

In this study we present a problematic case of conflicting conservation policies involving several threatened species. A small isolated population (20-30 individuals) of the mountain gazelle Gazella gazella acaciae inhabits a $6 \mathrm{~km}^{2}$ acacia forest near Yotvata in the southern Arava Valley, Israel (Yom-Tov \& Ilani, 1987; Dolev \& Perevolotsky, 2004). A recent genetic survey of gazelles in the Middle East showed that this isolated population is genetically different 
from the mountain gazelle Gazella gazella gazella in northern Israel but similar to G. gazella from northern Saudi Arabia (Wronski et al., 2010). This Critically Endangered G. g. acaciae population has been in decline since the 1960s, presumably because of low calf survival, low genetic diversity, anthropogenic effects and climate change (Yom-Tov \& Ilani, 1987; Dolev \& Perevolotsky, 2004; IUCN, 2008a). The congeneric dorcas gazelle Gazella dorcas is a more common species in the Negev but at a regional scale it is categorized as Vulnerable (Dolev \& Perevolotsky, 2004; IUCN, 2008b) because of intensive motorized hunting and habitat degradation caused by overgrazing and droughts (Mallon \& Kingswood, 2001). The law in Israel protects both gazelle species and poaching in the south of Israel is rare. The main alleged cause for the decline of both the mountain and dorcas gazelles in the Negev is predation by the Arabian wolf Canis lupus arabs and the caracal Caracal caracal, a hypothesis based on anecdotal data (Shalmon, 2003, 2006). The mountain and dorcas gazelles differ in their laying-up period, which is longer in the mountain gazelle, suggesting greater vulnerability of mountain gazelle fawns to predation (Mendelssohn et al., 1995; Yom-Tov et al., 1995). In response to the decline in gazelle populations in the southern Negev the Israel Nature and Parks Authority (INPA; the government agency that manages all natural resources in Israel) instigated a wolf removal programme that eliminated 37 individuals from the area during 2005-2008. By mid 2006 the isolated and small population of the mountain gazelle was completely fenced and the wolf removal programme was terminated in early 2008.

Although C. lupus is categorized as Least Concern on the IUCN Red List (Mech \& Boitani, 2010), the Arabian subspecies is threatened regionally and is vulnerable locally (Dolev \& Perevolotsky, 2004; Sillero-Zubiri et al., 2004) because of systematic shooting and trapping (Mendelssohn, 1983; Cunningham \& Wronski, 2010). In Israel the Arabian wolf is fully protected by law and is not persecuted except for specific management actions. Although Hefner \& Geffen (1999) have studied some behavioural aspects of this subspecies, no reliable demographic data are available. Hefner \& Geffen (1999) documented the dispersal of individuals over $50-150 \mathrm{~km}$, suggesting a continuous admixture between wolves in the southern and central Negev and the likelihood that the wolves in the Negev Desert comprise a single population.

Israel is divided into four INPA districts that are relatively independent of each other but controlled by a single directing body. The $13,000 \mathrm{~km}^{2}$ Negev Desert, which covers more than half of Israel, is divided into two INPA districts (Fig. 1). During 2005-2008 these two districts had different management policies for wolves. The Eilat district culled wolves by trapping or shooting (B. Shalmon, pers. comm.) and tightly controlled the access of carnivores to rubbish pits, although wolves may still have fed from garbage containers inside settlements and army camps. The South district, on the other hand, did not cull wolves and did not control access of wolves to local rubbish pits. Consequently, while the Eilat district attempted to reduce the wolf population to a minimum, the management exercised by the South district counteracted this. The above actions taken by INPA raise a question: how can a single population be managed by two contradictory policies? To address this issue we studied the genetic population structure and estimated population size using faecal DNA. Specifically, we examined whether the wolf population in the two INPA districts has similar densities and genetic composition. The findings of our study offer a new and reliable baseline for modification of the current INPA management policy for the Arabian wolf in the Negev Desert. Furthermore, our results can shed light on the effects of different management policies on the population genetics of a threatened species.

\section{Study area}

The central and southern Negev is a rocky desert, a mixture of mountains, washes, and depressions. The $160 \mathrm{~km}$ Arava Valley, an elongated depression of the Rift Valley, borders the Negev in the east. Elevation in the mountainous regions is $400-1,000 \mathrm{~m}$, falling to $50-150 \mathrm{~m}$ at the bottom of the Rift. The climate is hot and arid, with an annual rainfall of 50-100 $\mathrm{mm}$, falling during the winter months of NovemberMarch (Evenari et al., 1982). There are two cities, Eilat (population 50,000) at the northern tip of the Red Sea, and Mitzpe Ramon (population 6,000) in the Negev highlands. All other settlements are agricultural communities (10 in the Eilat district and eight in the South district), mostly in the Rift Valley.

\section{Methods}

\section{Sample collection}

To sample wolf scats equally over the central and southern Negev Desert we established a grid of 12 feeding sites c. $20 \mathrm{~km}$ apart. Five feeding sites were established in the Eilat district (sampling an area of c. 2,129 $\mathrm{km}^{2}$ ) and seven in the South district (sampling an area of c. 2,910 km²; Fig. 1). In setting out this grid of feeding sites we also considered vehicle accessibility and other entry restrictions. Mean home range size of Arabian wolves in the Negev Desert is $34.6 \pm \mathrm{SD} 19.5 \mathrm{~km}^{2}$ and mean daily travel distance is $13.7 \pm$ SD $6.7 \mathrm{~km}$ (maximum recorded distance travelled in a day is $42 \mathrm{~km}$; Hefner \& Geffen, 1999). Considering this mean daily travel distance all wolves in this area could probably reach at least one of the feeding sites on a daily basis. Once a month INPA rangers placed a cow calf carcass 


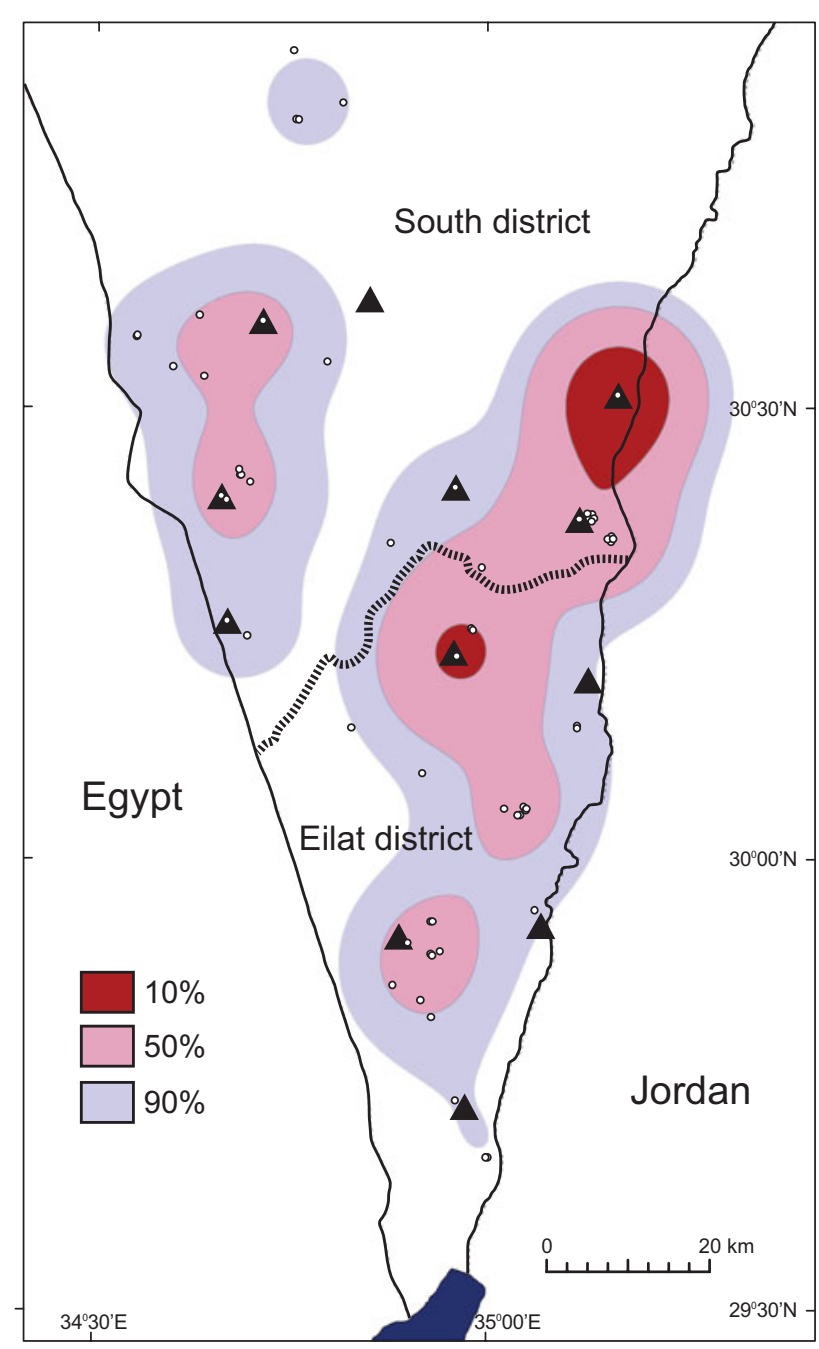

FIG. 1 Distribution of the 12 feeding sites (black triangles) used for collecting wolf Canis lupus arabs scats in the Negev Desert (see text for details). White circles denote locations where scats were collected. Kernel densities of 90, 50 and $10 \%$ for wolf scats are denoted. A single smoothing parameter of $h=10 \mathrm{~km}$ was used in all kernel contours. The heavy dashed line indicates the boundary between the south and Eilat INPA districts.

at each feeding site and scanned the site for scats 1 week later. Each calf carcass was secured to prevent removal by predators. The meat provided at each feeding site was insufficient to support local wolves but provided an incentive for resident wolves to inspect the site on a regular basis and defecate nearby. Because it is difficult to find wolf scats by random searches, except around garbage dumps, this system facilitated the sampling of individuals that are not associated with human habitation on a regular basis. Scats found on the routes leading to the feeding sites were also collected. Each scat was placed in a paper bag and the location and date of collection recorded. In this hot, arid environment, scats become dry a few hours after defecation and storage in paper bags keeps them dry and protected from condensation.
Genetic analysis

We extracted DNA from faecal samples using the protocol in Reed et al. (1997). Diagnostic mtDNA segments were used to confirm wolf DNA. We used 10 polymorphic wolf microsatellites to identify individuals. Details of the molecular procedures are outlined in Supplementary Information 1.

We used two population genetic approaches to examine whether a spatial correspondence exists between genetic and spatial grouping (i.e. INPA districts) of wolves. Details of the relatedness network analysis are provided in Supplementary Information 1.

\section{Bayesian clustering}

To assign individuals to populations we used STRUCTURE 2.3.1 (Pritchard et al., 2000), which uses multi-locus genotypes $(\mathrm{X})$ to infer population structure. The Bayesian model assumes $K$ populations that have different allele frequencies within a set of independent loci. We applied the admixture ancestry model once with the independent allele frequency model and once with the correlated model. The number of populations $(K)$ was modified from 1 to 10. For each value of $K 10$ independent simulations were run for each of the two allele frequency models. Each simulation had a burn-in period of 500,000 iterations followed by a sampling of 500,000 iterations. The likelihood of $K$ (i.e. $\mathrm{Ln}$ $\operatorname{Pr}(X \mid K))$ and $\Delta K$ (Evanno et al., 2005) were used to infer the more likely number of populations. This algorithm also calculates a membership coefficient $(Q)$ for each individual in each population. We used the highest $Q$ value to assign each individual to a population.

\section{Population size estimation}

We used three different approaches to estimate the wolf population size in the Negev: rarefaction curves, capturemark-recapture, and a simple urn model called Capwire.

Rarefaction curve In this technique the data are plotted as the number of unique multi-locus genotypes (i.e. individuals) as a function of sample size (number of scats analysed) and then fitted to a curve. The asymptote of the curve provides an estimate of the population size. Three fitting equations have been employed in similar previous studies: $y=a x /(b+x)$ (Kohn et al., 1999), $y=a\left(1-e^{-b x}\right)$ (Eggert et al., 2003) and $y=a-a(1-1 / a)^{x}$, which was developed by D. Chessel (Frantz \& Roper, 2006). In all equations $a$ is the asymptote, $b$ determines the rate of decrease of the slope, $x$ is the number of scats sampled, and $y$ is the number of unique genotypes. We used GIMLET to generate rarefaction curves (Valiere, 2002). Because the order in which DNA samples are added has an influence on the shape of the curve 
(Kohn et al., 1999) we used $R$ 2.10.1 (Ihaka \& Gentleman, 1996) to randomize (1,000 iterations) the order of the DNA samples and projected the asymptote for each of these randomizations using each of the three equations. The median of all 1,00o iterations of the asymptote was taken as an estimate of the population size (Frantz \& Roper, 2006). The $95 \%$ confidence interval (CI) corresponds to the 0.025 and 0.975 percentiles.

Capture-mark-recapture (CMR) model The study design (i.e. sampling at the feeding stations at monthly intervals) allowed us to easily adapt the genetic data to the CMR model. Identical multi-locus genotypes were considered to originate from the same individual and a history of captures and recaptures was assembled for each genotype. We divided the study period into 20 monthly sampling sessions. If the same genotype was sampled more than once in the same month we considered only one capture for that month. Analysis was performed with an open population model, using the POPAN module in MARK (White \& Burnham, 1999). We used a set of four possible models: fully time dependent $(p t, \varphi t, b t)$ where $p$ represents the probability of capture, $\varphi$ represents the probability of an animal surviving between occasions and $b$ is probability of entrance; constant catchability $(p \cdot, \varphi t, b t)$; constant survival rate $(p t, \varphi \cdot, b t)$; and constant catchability and survival rate $(p \cdot, \varphi, b t)$. We performed a goodness-of-fit using the RELEASE suite (Cooch \& White 2007) to confirm that the most general sub-model adequately fitted the data. MARK uses $\mathrm{AIC}_{\mathrm{c}}$ (Akaike's information criterion corrected for small sample size) for model selection.

Capture with replacement In non-invasive sampling individuals may be 'captured' several times within one sampling session. When using classical CMR models such multiple captures must be pooled, as an animal should not be captured more than once in one session. This potentially wastes data. Capwire (Miller et al., 2005) uses a method developed to accommodate this type of data and is based on a simple urn model. There are two capture models: the even capture probability model (ECM) in which every individual is equally likely to be captured in each sampling session with a probability of $1 /$ population size, and the two innate rates model (TIRM), which is more realistic, in which there are two types of individuals with different probabilities of capture. The software performs a likelihood-ratio test to determine which model is more suitable for the given data.

\section{Results}

Sample collection and microsatellite genotype

Over a period of 20 months from May 2007 to December 2008 a total of 334 faecal samples were collected and an additional three tissue samples were taken from wolves that
TABLE 1 The number of alleles, observed $\left(H_{\mathrm{obs}}\right)$ and expected $\left(H_{\text {exp }}\right)$ heterozygosity, and the rate of allelic dropout and false alleles for each of the to loci used in this study.

\begin{tabular}{lcccll}
\hline Locus & $\begin{array}{c}\text { No. of } \\
\text { alleles }\end{array}$ & $H_{\text {obs }}$ & $H_{\text {exp }}$ & $\begin{array}{l}\text { Allelic } \\
\text { dropout }\end{array}$ & $\begin{array}{l}\text { False } \\
\text { alleles }\end{array}$ \\
\hline CXX618 & 7 & 0.80 & 0.72 & 0.040 & 0.018 \\
FH2137 & 14 & 0.87 & 0.84 & 0.062 & 0.174 \\
FH2010 & 6 & 0.62 & 0.55 & 0.073 & 0.259 \\
FH2175 & 9 & 0.76 & 0.73 & 0.068 & 0.066 \\
CXX733 & 9 & 0.79 & 0.75 & 0.157 & 0.017 \\
FH2079 & 7 & 0.67 & 0.68 & 0.128 & 0.164 \\
CXX140 & 7 & 0.75 & 0.79 & 0.041 & 0.092 \\
CXX250 & 5 & 0.93 & 0.76 & 0.025 & 0.123 \\
CXX251 & 6 & 0.58 & 0.63 & 0.031 & 0.146 \\
CXX758 & 7 & 0.55 & 0.74 & 0.049 & 0.073 \\
Mean & 7.7 & 0.73 & 0.72 & 0.068 & 0.113 \\
\hline
\end{tabular}

had been shot by INPA rangers. Most scats (82\%) were collected after the wolf control programme was terminated. Mitochondrial DNA for species identification was successfully amplified in 230 (69\%) of the faecal samples, of which 95 were identified as wolf DNA, 93 were of red foxes Vulpes vulpes, 12 of dogs Canis lupus familiaris, nine of golden jackals Canis aureus and two of striped hyaenas Hyaena hyaena. In $5 \%$ of the samples that were identified, mtDNA of the prey (Ovis aries, Capra hircus, Bos taurus) rather than the predator was amplified.

Of the 98 wolf DNA samples (i.e. 95 faecal samples plus three tissue samples) we obtained a complete or nearly complete multi-locus genotype for 76 samples. The mean rate of allelic dropout was 0.068 and mean rate of false alleles was 0.113 for all replicates at all microsatellite loci. The probability of two individuals possessing identical genotypes (PI) was $1.40 \times 10^{-10}$ for a randomly mated population and $1.635 \times 10^{-4}$ for siblings. Error rates and PI values of each locus were calculated using GIMLET (Table 1, Supplementary Information 1). We identified 52 unique haplotypes of which 12 were sampled more than once, with a mean of 1.46 samples per individual. The maximum resample rate was $\operatorname{six}(n=2)$.

\section{Population structure}

We used the Bayesian model in the programme STRUCTURE. The highest $\operatorname{Ln} \operatorname{Pr}(X \mid K)$ and $\Delta K$ were observed for $K=3$, indicating three genetic subpopulations (Figs 2 \& 3a). This result was consistent for both correlated and independent allele frequency models. Most sampled individuals were easily assigned to a cluster as their estimated membership coefficient $(Q)$ was $>0.7$ for a specific population. However, three individuals (15, 7, and 11) could not be assigned because their $Q$ values were $\leqslant 0.7$ (Fig. 3a).

The distribution of two of the genetic populations $\left(\mathrm{C}_{3}\right.$ and C1; Fig. 3b) did not show any clear spatial separation 

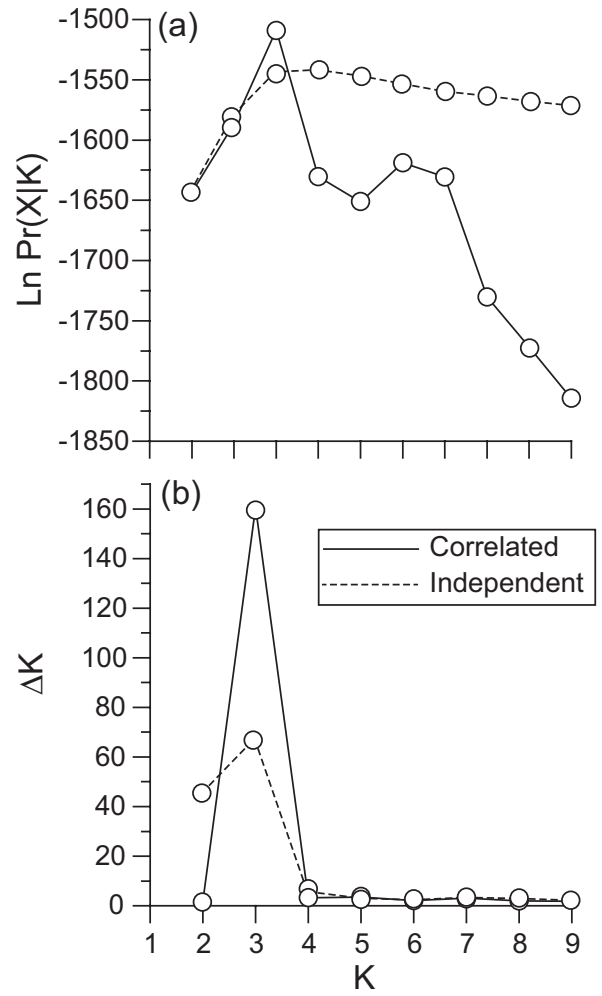

FIG. 2 Number of subpopulations inferred by STRUCTURE. (a) Mean $\operatorname{Ln} \operatorname{Pr}(X \mid K)$ over 10 runs for each $K$ value. (b) $\Delta K$ for each $K$ value, where $\Delta K=m|L(K+1)-2 L(K)+L(K-1)| / s[L(K)]$. Both Ln $\operatorname{Pr}(X \mid K)$ and $\Delta K$ were calculated for the correlated and independent models.

between INPA districts. In Eilat district six individuals were of the $\mathrm{C}_{1}$ cluster and 10 of the $\mathrm{C}_{3}$ cluster, and in the South district 10 individuals were of the $\mathrm{C}_{1}$ cluster and eight of the $\mathrm{C}_{3}$ cluster (Fig. 3b). However, a third population (C2; Fig. $3 \mathrm{~b})$ had most individuals $(\mathrm{n}=13)$ in the South district and only one individual in the Eilat district. Thus, the division between districts was significantly dependent on genetic clustering $\left(\chi_{2}^{2}=8.114, \mathrm{P}=0.0172\right)$ because of the uneven distribution of the $\mathrm{C}_{2}$ cluster members between districts (Fig. 3b).

\section{Population size estimation}

The Kohn rarefaction equation gave the highest population estimate, of 176.8 wolves (95\% CI 120.8-491.4), followed by that of Eggert with an estimate of 102.1 (95\% CI 74.4-256.2), and Chessel with the lowest estimate of 86.2 wolves (95\% CI 72.1-105.3; Table 2). The TIRM model of Capwire (L(TIRM) $-L(\mathrm{ECM})=22.48)$ gave an estimate of 142 wolves $(95 \% \mathrm{CI}$ 89-179). For the CMR model the goodness-of-fit test confirmed that the most general sub-model adequately fitted the data $\left(\chi_{11}^{2}=3.447, \quad \mathrm{P}=0.983\right)$. The constant catchability and constant survival rate model ranked highest by AICc and gave an estimate of 173.4 wolves (95\% CI 85.6-261.1; Table 3).
A separate population estimation for each district showed that although the number of wolves in the Eilat district was considerably lower than in the South district, the density of wolves was similar in both districts based on the rarefaction estimates but higher in the South district based on the CMR and Capwire estimates (Table 2). CMR models showed that the lowest $\mathrm{AIC}_{\mathrm{c}}$ value was obtained by the constant catchability model for the South district and the constant catchability and survival rate model for the Eilat district (Table 3).

\section{Discussion}

Our results show that the wolf populations in the two INPA districts had a similar genetic composition. The Bayesian model in STRUCTURE identified three genetic subpopulations: two distributed across both districts, and one mostly in the South district (Fig. 3). However about half of the individuals of the latter population were found near the south-eastern corner of the South district, at the border between the districts. Additional sampling would probably reveal their presence in the north-eastern corner of the Eilat district. Furthermore, network analysis of relatedness shows that individuals of both communities are present in both INPA districts in approximately equal proportions (Supplementary Fig. S1). Taken together, the evidence for considering the wolves in the two districts as separate, distinct populations is weak. Overall, our data suggest that all the wolves in the Negev Desert comprise a single population, which should therefore be managed as a single conservation unit. This view is supported by the extensive dispersal distance of Arabian wolves in the Negev (Hefner \& Geffen, 1999), implying that no isolation exists between wolf populations living throughout this region.

In these contradictory management approaches between the two INPA districts priority has been given to gazelles over wolves. This situation could have been avoided through a more balanced ecosystem approach that considers the ecological role of both species. The Arabian wolf is currently the top predator in this system, and the gazelle (mostly $G$. dorcas) is one of the largest native ungulates together with the Nubian ibex Capra ibex nubiana, onager Equus hemionus and Arabian oryx Oryx leucoryx. The latter two species were recently reintroduced into the Negev Desert. Both wolves and gazelles have key ecological roles in the Negev ecosystem (Mendelssohn \& Yom-Tov, 1999).

Does the Arabian wolf exert a significant impact on the gazelle population? This issue has never been systematically studied in the Negev Desert. Our findings indicate that the number of wolves in the southern Negev (i.e. Eilat district) is c. $30-50$, whereas $60-100$ inhabit the central Negev (i.e. South district). Both gazelle species have been counted annually in the Negev Desert since the 1970s. The mountain 
(a)

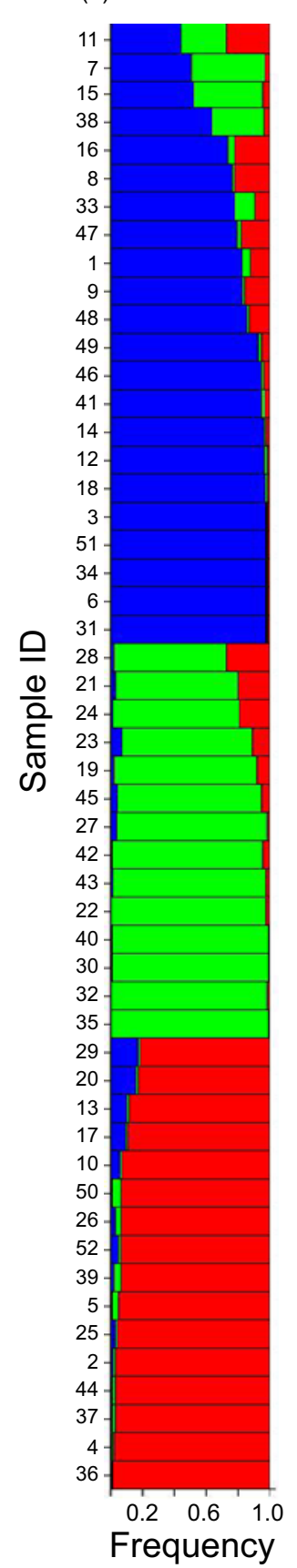

(b)

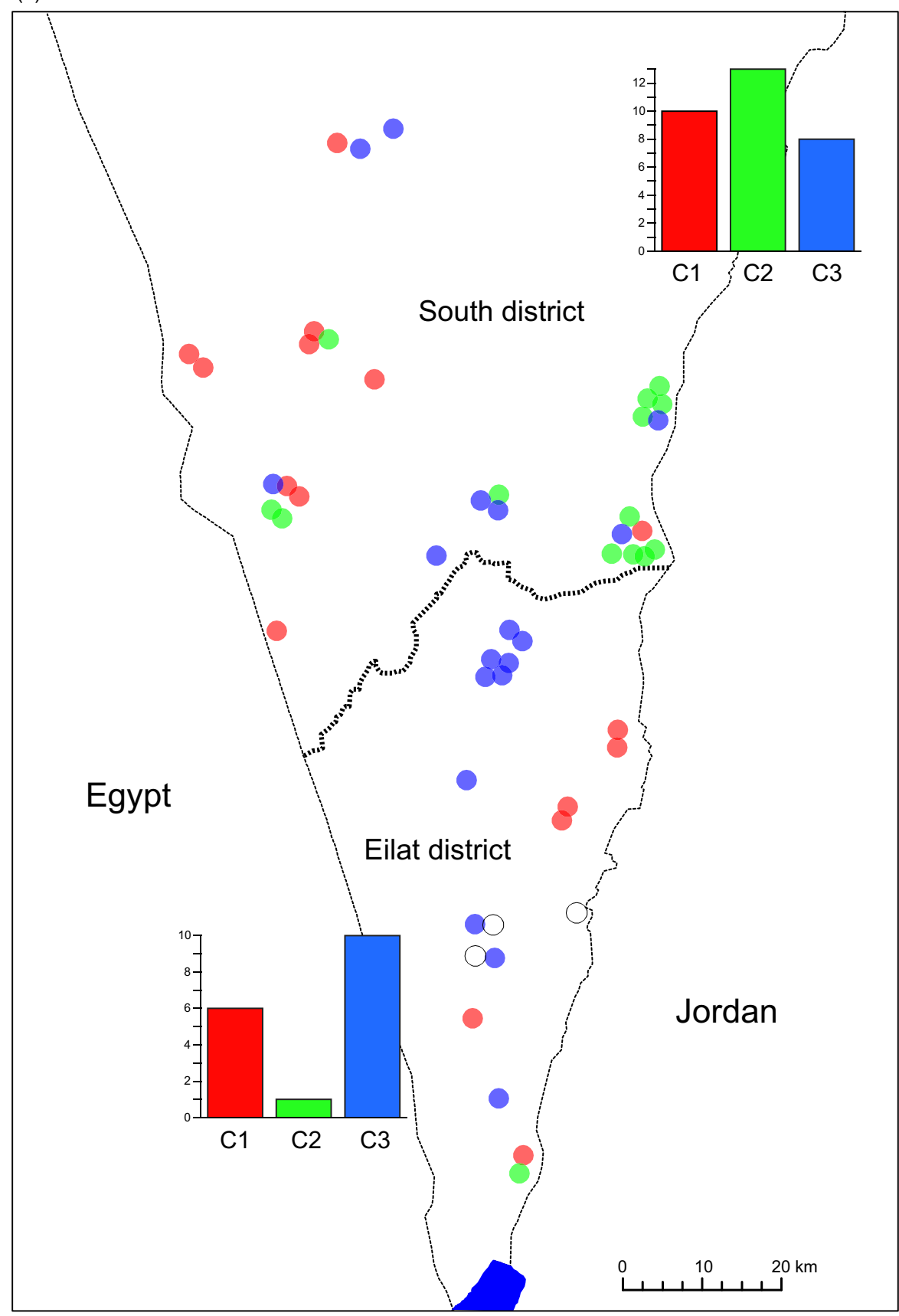

FIG. 3 Assignment of haplotypes by the STRUCTURE Bayesian algorithm. (a) Probability of belonging to each of three clusters $(K=3)$ is denoted by shading (as in (b)). (b) Spatial distribution of haplotypes, assigned to the cluster with the highest probability. Empty circles are haplotypes that could not be assigned to a cluster. The frequency of each cluster $\left(\mathrm{C}_{1}, \mathrm{C}_{2}, \mathrm{C}_{3}\right)$ in each of the districts is indicated by a bar chart. The heavy dashed line indicates the boundary between INPA districts.

gazelle population is restricted to a single locality in Eilat district and has numbered c. $\leqslant 40$ since 1978 (Yom-Tov \& Ilani, 1987; Dolev \& Perevolotsky, 2004). Thus, the significance of mountain gazelle to the overall Negev ecosystem is negligible. However, the dorcas gazelle is widespread in the Negev, with densities reaching $5 \mathrm{~km}^{-2}$ in areas where many acacias are present and $0.1 \mathrm{~km}^{-2}$ in areas without acacias (Baharav, 1980). Based on total counts the population size of the dorcas gazelle in the Negev during 1980-1985 was estimated at 1,000-1,300 (Yom-Tov \& Ilani, 1987; Mallon \& Kingswood, 2001). During 1971-2009 the number of dorcas gazelles was 500-900 in the Eilat district (B. Shalmon, unpubl. data) and $150-550$ in the South district (B. Shalmon \& A. Tsoar, unpubl. data). Dorcas gazelle numbers in the Eilat district have fluctuated considerably in the past 40 years (Yom-Tov \& Ilani, 1987); however, there 
TABLE 2 Mean population size and mean density of the Arabian wolf Canis lupus arabs in the Negev Desert, and in the South and Eilat INPA districts separately (Fig. 1), based on five estimation methods (see text for details).

\begin{tabular}{|c|c|c|c|c|c|}
\hline \multirow[b]{2}{*}{ Area } & \multirow[b]{2}{*}{ MARK } & \multirow[b]{2}{*}{ Capwire } & \multicolumn{3}{|l|}{ Rarefaction } \\
\hline & & & Chessel & Eggert & Kohn \\
\hline \multicolumn{6}{|l|}{ Negev Desert } \\
\hline Mean population size $(95 \% \mathrm{CI})$ & $173.4(85.7-261.1)$ & $142.0(89.0-179.0)$ & $86.2(72.1-105.3)$ & $102.1(74.4-256.2)$ & $176.8(120.8-491.4)$ \\
\hline Density $\left(100 \mathrm{~km}^{-2}\right)$ & 3.4 & 2.8 & 1.7 & 2.0 & 3.5 \\
\hline \multicolumn{6}{|l|}{ South district } \\
\hline Mean population size $(95 \% \mathrm{CI})$ & $98.9(10.7-187.1)$ & $86.0(46.0-116.0)$ & $44.5(36.1-57.3)$ & $60.6(38.1-363.7)$ & $106.0(60.5-916.0)$ \\
\hline Density $\left(100 \mathrm{~km}^{-2}\right)$ & 3.4 & 3.0 & 1.5 & 2.1 & 3.6 \\
\hline \multicolumn{6}{|l|}{ Eilat district } \\
\hline Mean population size $(95 \% \mathrm{CI})$ & $47.6(19.3-76.0)$ & $33.0(23.0-52.0)$ & $33.3(25.8-44.1)$ & $33.1(24.4-97.9)$ & $55.4(37.8-194.6)$ \\
\hline Density $\left(100 \mathrm{~km}^{-2}\right)$ & 2.2 & 1.6 & 1.6 & 1.6 & 2.6 \\
\hline
\end{tabular}

TABLE 3 Selection of MARK models (see text for details) for the Negev Desert population and INPA South and Eilat district populations separately.

\begin{tabular}{|c|c|c|c|c|c|}
\hline Model & Parameters & $\mathrm{AIC}_{\mathrm{c}}^{1}$ & $\Delta \mathrm{AIC}_{\mathrm{c}}^{2}$ & WAIC $^{3}$ & $L_{\text {model }}^{4}$ \\
\hline \multicolumn{6}{|l|}{ Negev Desert } \\
\hline Constant catchability \& survival rate $(p \cdot, \varphi \cdot, b t)$ & 22 & 249.6 & 0.0 & 1.00 & 1.0 \\
\hline Constant catchability $(p \cdot, \varphi t, b t)$ & 40 & 377.3 & 127.7 & 0.00 & 0.0 \\
\hline Constant survival rate $(p t, \varphi \cdot b t)$ & 41 & 389.3 & 139.7 & 0.00 & 0.0 \\
\hline Time dependent model $(p t, \varphi t, b t)$ & 57 & $1,094.7$ & 845.1 & 0.00 & 0.0 \\
\hline \multicolumn{6}{|l|}{ South district } \\
\hline Constant catchability \& survival rate $(p \cdot, \varphi \cdot, b t)$ & 13 & 132.9 & 16.4 & 0.00 & 0.0 \\
\hline Constant catchability $(p \cdot, \varphi t, b t)$ & 14 & 116.5 & 0.0 & 0.91 & 1.0 \\
\hline Time dependent model $(p t, \varphi t, b t)$ & 16 & 121.1 & 4.6 & 0.09 & 0.1 \\
\hline Constant survival rate $(p t, \varphi \cdot b t)$ & 26 & 314.6 & 198.1 & 0.00 & 0.0 \\
\hline \multicolumn{6}{|l|}{ Eilat district } \\
\hline Constant catchability \& survival rate $(p \cdot, \varphi \cdot, b t)$ & 10 & 151.9 & 0.0 & 1.00 & 1.0 \\
\hline Constant catchability $(p \cdot, \varphi t, b t)$ & 14 & 164.5 & 12.6 & 0.00 & 0.0 \\
\hline Constant survival rate $(p t, \varphi \cdot, b t)$ & 19 & 216.1 & 64.2 & 0.00 & 0.0 \\
\hline Time dependent model $(p t, \varphi \cdot, b t)$ & 21 & 261.9 & 111.0 & 0.00 & 0.0 \\
\hline
\end{tabular}

${ }^{1} \mathrm{AIC}$ value corrected for small sample sizes ${ }^{2}$ Difference in $\mathrm{AIC}_{\mathrm{c}}$ between the focal and the best model ${ }^{3} \mathrm{AIC}$ weight ${ }^{4}$ Model likelihood

are no comparable annual data on wolf numbers to support the claim that these fluctuations are related to predation. Nor is reliable data on predation of fawn or adult mountain and dorcas gazelle species available for the Negev population. Analysis of 777 wolf scats from the southern Negev (Shalmon, 1986) revealed that the major dietary components of Arabian wolves are cow carrion (found in $62.5 \%$ of scats), fruit and vegetation ( $51.4 \%$ of scats) and human garbage $(37.2 \%$ of scats). The frequency of indigenous prey, including gazelles, in the scats was only 6.3\%. In North America Messier et al. (1995) showed that the number of wolves per area is linearly related to the density of deer-sized prey. In these populations, wolves consumed mainly large ungulates (northern Minnesota, Kunkel \& Mech, 1994; Isle Royale National Park, Vucetich et al., 2002; Yellowstone National Park, Wright et al., 2006) In contrast, the Arabian wolves in the Negev seem to be dependent on human-related waste and domestic livestock and seldom rely on natural prey.
The implications of our results are that a major change in wolf management in both INPA districts is required. Firstly, Arabian wolves should not be culled without a robust corresponding study on the effects of such action. The Arabian wolf is a threatened species, living in an arid zone with limited resources (Dolev \& Perevolotsky, 2004; SilleroZubiri et al., 2004). Its population fluctuates similarly to other species dwelling in this region, and may reach critical low levels. Furthermore, culling is indiscriminate and could thus inadvertently eliminate a distinct genotype and thereby reduce the evolutionary potential for survival of this population. Secondly, we suggest that reducing access to human-related waste and domestic livestock could adjust the wolf population size to this arid environment's natural carrying capacity by forcing the wolf population to feed more on natural prey. Thirdly, the effect of droughts and habitat modification by human activity on the dorcas gazelle population in the Negev should be systematically investigated before further culling of predators is carried out. 
At present, both districts are modifying their management policies with respect to wolves. Wolf culling has been terminated, and new programmes are being developed for limiting the access of carnivores to human waste and agriculture surplus. We have also developed a study on wolf resource utilization, using GPS collars, to understand the dependency of wolves on human resources. Finally, we call for more detailed study on the population dynamics of gazelles in the Negev, especially in relation to effects of global warming, before instigating any further predator control programmes in this region.

\section{Acknowledgements}

We would like to thank Shirley Bar-David, Naomi Paz, Uri Roll, Benny Shalmon and Yoram Yom-Tov for constructive comments, and Nimrod Ben-Aharon, Mark Catz, Ben Drori, Gil Evron, Ariela Gotlieb, Reuven Hefner, Yoram Hemo, Tzoor Magen and Enav Vidan for maintaining the feeding sites and assisting in the collection of scats. The Israel Nature and Parks Authority provided logistic and financial support.

\section{References}

Baharav, D. (1980) Habitat utilization of the dorcas gazelle in a desert saline area. Journal of Arid Environments, 3, 161-167.

Ballard, W.B., Lutz, D., Keegan, T.W., Carpenter, L.H. \& De Vos, J.C. (2001) Deer-predator relationships: a review of recent North American studies with emphasis on mule and black-tailed deer. Wildlife Society Bulletin, 29, 99-115.

Carmichael, L.E., Krizan, J., Nagy, J.A., Fuglei, E., Dumond, M., Johnson, D. et al. (2007) Historical and ecological determinants of genetic structure in arctic canids. Molecular Ecology, 16, $3466-3483$.

Coоch, E.G. \& White, G.C. (2001) Program MARK. A gentle introduction. Analysis of data from marked individuals, Vol. 2007. Http://www.phidot.org/software/mark/docs/book [accessed 4 January 2013].

Courchamp, F., Chapuis, J.L. \& Pascal, M. (2003) Mammal invaders on islands: impact, control and control impact. Biological Reviews, 78, 347-383.

Cunningham, P.L. \& Wronski, T. (2010) Arabian wolf distribution update from Saudi Arabia. Canid News, 13, 1-6.

Dolev, A. \& Perevolotsky, A. (2004) The Red Book: Vertebrates in Israel. Israel Nature and Parks Authority and The Society for the Protection of Nature in Israel. Gefen Books, New York, USA.

Eggert, L.S., Eggert, J.A. \& Woodruff, D.S. (2003) Estimating population sizes for elusive animals: the forest elephants of Kakum National Park, Ghana. Molecular Ecology, 12, 1389-1402.

Evanno, G., Regnaut, S. \& Goudet, J. (2005) Detecting the number of clusters of individuals using the software STRUCTURE: a simulation study. Molecular Ecology, 14, 2611-2620.

Evenari, M., Shanan, L. \& Tadmor, N. (1982) The Negev: The Challenge of a Desert. Harvard University Press, Cambridge, USA.

Francisco, L.V., Langston, A.A., Mellersh, C.S., Neal, C.L. \& Ostrander, E.A. (1996) A class of highly polymorphic tetranucleotide repeats for canine genetic mapping. Mammalian Genome, 7, 359-362.

Frantz, A.C. \& Roper, T.J. (2006) Simulations to assess the performance of different rarefaction methods in estimating population size using small datasets. Conservation Genetics, 7 , 315-318.

FreEMAN, L.C. (1977) A set of measures of centrality based on betweenness. Sociometry, 40, 35-41.

Girvan, M. \& Newman, M.E.J. (2002) Community structure in social and biological networks. Proceedings of the National Academy of Sciences of the United States of America, 99, 7821-7826.

Hefner, R. \& Geffen, E. (1999) Group size and home range of the Arabian wolf (Canis lupus) in southern Israel. Journal of Mammalogy, 80, 611-619.

Ihaka, R. \& Gentleman, R. (1996) R: a language for data analysis and graphics. Journal of Computational and Graphical Statistics, 5, 299-314.

IUCN SSC Antelope Specialist Group (2008a) Gazella gazella. In The IUCN Red List of Threatened Species v. 2012.1. Http://www. iucnredlist.org [accessed 4 January 2013].

IUCN SSC Antelope Specialist Group (2008b) Gazella dorcas. In The IUCN Red List of Threatened Species v. 2012.1. Http://www. iucnredlist.org [accessed 4 January 2013].

Kalinowski, S.T., Wagner, A.P. \& Taper, M.L. (2006) ML-RELATE: a computer program for maximum likelihood estimation of relatedness and relationship. Molecular Ecology Notes, 6, 576-579.

Kohn, M.H., York, E.C., Kamradt, D.A., Haugt, G., SAUVAJOT, R.M. \& WAYNE, R.K. (1999) Estimating population size by genotyping faeces. Proceedings of the Royal Society of London Series B Biological Sciences, 266, 657-663.

KunKeL, K.E. \& MECH, L.D. (1994) Wolf and bear predation on white-tailed deer fawns in north-eastern Minnesota. Canadian Journal of Zoology, 72, 1557-1565.

Lucchini, V., Fabbri, E., Marucco, F., Ricci, S., Boitani, L. \& RANDI, E. (2002) Noninvasive molecular tracking of colonizing wolf (Canis lupus) packs in the western Italian Alps. Molecular Ecology, 11, 857-868.

Mallon, D.P. \& Kingswood, S.C. (2001) Antelopes. Part 4: North Africa, the Middle East, and Asia. Global Survey and Regional Action Plans. Species Survival Commission Antelope Specialist Group. IUCN, Gland, Switzerland, and Cambridge, UK.

Mech, L.D. \& Boitani, L. (2010) Canis lupus. In The IUCN Red List of Threatened Species $v$. 2012.1. Http://www.iucnredlist.org [accessed 4 January 2013].

Mendelssohn, H. (1983) Status of the wolf in the Middle East. Acta Zoologica Fennica, 174, 279-280.

Mendelssohn, H. \& Yom-Tov, Y. (1999) Mammalia of Israel. The Israel Academy of Sciences and Humanities, Jerusalem, Israel.

Mendelssohn, H., Yom-Tov, Y. \& Groves, C.P. (1995) Gazella gazella. Mammalian Species, 490, 1-7.

Messier, F., Carbyn, L.N., Fritts, S.H. \& Seip, D.R. (1995) On the functional and numerical responses of wolves to changing prey density. In Ecology and Conservation of Wolves in a Changing World (eds L.N. Carbyn, S.H. Fritts \& D.R. Seip), pp. 187-197. Canadian Circumpolar Institute, Edmonton, Canada.

Miller, C.R., Joyce, P. \& Waits, L.P. (2005) A new method for estimating the size of small populations from genetic markrecapture data. Molecular Ecology, 14, 1991-2005.

Newman, M.E.J. \& Girvan, M. (2004) Finding and evaluating community structure in networks. Physical Review E, 69, 026113.

Ostrander, E.A., Mapa, F.A., Yee, M. \& Rine, J. (1995) One hundred and one new simple sequence repeat-based markers for the canine genome. Mammalian Genome, 6, 192-195. 
Ostrander, E.A., Sprague, G.F. \& Rine, J. (1993) Identification and characterization of dinucleotide repeat $(\mathrm{CA})_{\mathrm{n}}$ markers for genetic mapping in dog. Genomics, 16, 207-213.

Pritchard, J.K., Stephens, M. \& Donnelly, P. (2000) Inference of population structure using multilocus genotype data. Genetics, 155, 945-959.

Randi, E. \& Lucchini, V. (2002) Detecting rare introgression of domestic dog genes into wild wolf (Canis lupus) populations by Bayesian admixture analyses of microsatellite variation. Conservation Genetics, 3, 31-45.

Reed, J.Z., Tollit, D.J., Thompson, P.M. \& Amos, W. (1997) Molecular scatology: the use of molecular genetic analysis to assign species, sex and individual identity to seal faeces. Molecular Ecology, $6,225-234$.

Roemer, G.W., Donlan, C.J. \& Courchamp, F. (2002) Golden eagles, feral pigs, and insular carnivores: how exotic species turn native predators into prey. Proceedings of the National Academy of Sciences of the United States of America, 99, 791-796.

Roemer, G.W. \& WAyne, R.K. (2003) Conservation in conflict: the tale of two endangered species. Conservation Biology, 17, 1251-1260.

Rozenfeld, A.F., Arnaud-Haond, S., Hernandez-Garcia, E., Eguiluz, V.M., Serrao, E.A. \& Duarte, C.M. (2008) Network analysis identifies weak and strong links in a metapopulation system. Proceedings of the National Academy of Sciences of the United States of America, 105, 18824-18829.

Scandura, M., Capitani, C., Iacolina, L. \& Marco, A. (2006) An empirical approach for reliable microsatellite genotyping of wolf DNA from multiple noninvasive sources. Conservation Genetics, 7 , $813-823$.

Shalmon, B. (1986) Wolves in the southern Arava. Re'em, 5, 60-74. [in Hebrew]

Shalmon, B. (2003) Wolves versus mountain gazelles: a proposal for culling wolves in the area between Samar and Yotvata. Unpublished Report. The Israel Nature and Parks Authority, Jerusalem, Israel. [in Hebrew]

Shalmon, B. (2006) Wolves in the Arava Valley: carrying capacity and population size. Unpublished Report. The Israel Nature and Parks Authority, Jerusalem, Israel. [in Hebrew]

Sillero-Zubiri, C., Hoffmann, M., \& Macdonald, D.W. (2004) Canids: Foxes, Wolves, Jackals and Dogs: Status Survey and Conservation Action Plan. IUCN, Cambridge, UK.

Smith, R.K., Pullin, A.S., Stewart, G.B. \& Sutherland, W.J. (2010) Effectiveness of predator removal for enhancing bird populations. Conservation Biology, 24, 820-829.
Taberlet, P., Griffin, S., Goossens, B., Questiau, S., Manceau, V., Escaravage, N. et al. (1996) Reliable genotyping of samples with very low DNA quantities using PCR. Nucleic Acids Research, 24, 3189-3194.

VALIERE, N. (2002) GIMLET: a computer program for analysing genetic individual identification data. Molecular Ecology Notes, 2, 377-379.

Vila, C., Amorim, I.R., Leonard, J.A., Posada, D., Castroviejo, J., Petrucci-Fonseca, F. et al. (1999) Mitochondrial DNA phylogeography and population history of the grey wolf Canis lupus. Molecular Ecology, 8, 2089-2103.

Vucetich, J.A., Peterson, R.O. \& Schaefer, C.L. (2002) The effect of prey and predator densities on wolf predation. Ecology, 83, 3003-3013.

Wasser, S.K., Keim, J.L., TAper, M.L. \& Lele, S.R. (2011) The influences of wolf predation, habitat loss, and human activity on caribou and moose in the Alberta oil sands. Frontiers in Ecology and the Environment, 9, 546-551.

Wayne, R.K., Geffen, E., Girman, D.J., Koepfli, K.P., Lau, L.M. \& Marshall, C.R. (1997) Molecular systematics of the Canidae. Systematic Biology, 46, 622-653.

White, G.C. \& Burnham, K.P. (1999) Program MARK: survival estimation from populations of marked animals. Bird Study, 46, 120-139.

Wright, G.J., Peterson, R.O., Smith, D.W. \& Lemke, T.O. (2006) Selection of northern Yellowstone elk by gray wolves and hunters. Journal of Wildlife Management, 70, 1070-1078.

Wronski, T., Wacher, T., Hammond, R.L., Winney, B., Hundertmark, K.J., Blacket, M.J. et al. (2010) Two reciprocally monophyletic mtDNA lineages elucidate the taxonomic status of mountain gazelles (Gazella gazella). Systematics and Biodiversity, 8 , 119-129.

Yom-Tov, Y. \& ILani, G. (1987) The numerical status of Gazella dorcas and Gazella gazella in the Southern Negev Desert, Israel. Biological Conservation, 40, 245-253.

Yom-Tov, Y., Mendelssohn, H. \& Groves, C.P. (1995) Gazella dorcas. Mammalian Species, 491, 1-6.

\section{Biographical sketches}

ORLY COHEN is interested in applying molecular approaches to ecological and conservation-related problems. ADI BAROCAS is a behavioural ecologist interested in the effects of social integration and complexity on survival. $\mathrm{He}$ is also interested in conservation and management of carnivores. ELI GEFFEN has broad, global interests in behaviour, genetics and conservation of canids. 